\title{
Human immunodeficiency virus infection in pregnancy
}

\author{
Yasemin Arikan MD FRCPC ${ }^{1}$, David R Burdge MD FRCPC ${ }^{2}$
}

\begin{abstract}
Y Arikan, DR Burdge. Human immunodeficiency virus infection in pregnancy. Can J Infect Dis 1998;9(5):301-309.
The incidence and prevalence of human immunodeficiency virus (HIV) infection in women of child-bearing age continue to increase both internationally and in Canada. The care of HIV-infected pregnant women is complex, and multiple issues must be addressed, including the current and future health of the woman, minimization of the risk of maternalinfant HIV transmission, and maintenance of the well-being of the fetus and neonate. Vertical transmission of HIV can occur in utero, intrapartum and postpartum, but current evidence suggests that the majority of transmission occurs toward end of term, or during labour and delivery. Several maternal and obstetrical factors influence transmission rates, which can be reduced by optimal medical and obstetrical care. Zidovudine therapy has been demonstrated to reduce maternal-infant transmission significantly, but several issues, including the short and long term safety of antiretrovirals and the optimal use of combination antiretroviral therapy in pregnancy, remain to be defined. It is essential that health care workers providing care to these women fully understand the natural history of HIV disease in pregnancy, the factors that affect vertical transmission and the management issues during pregnancy. Close collaboration among a multidisciplinary team of knowledgeable health professionals and, most importantly, the woman herself can improve both maternal and infant outcomes.
\end{abstract}

Key Words: AIDS, Antiretroviral therapy, Human immunodeficiency virus, Pregnancy, Zidovudine

\section{L'infection au virus de l'immunodéficience humaine pendant la grossesse}

RÉSUMÉ : L'incidence et la prévalence de l'infection au virus de l'immunodéficience humaine (VIH) chez les femmes en âge de procréer ne cessent de s'accroître à la fois dans le monde et au Canada. La prise en charge des femmes enceintes infectées par le VIH est complexe, et de nombreuses questions doivent être abordées y compris l'état de santé présent et futur de la femme, la minimisation du risque de transmission du VIH par la mère à l'enfant, et la protection du bien-être $\mathrm{du}$ fœtus et du nouveau-né. La transmission verticale du VIH peut survenir in utero, au moment de l'accouchement ou après l'accouchement, mais les données actuelles permettent de croire que la transmission survient en grande partie vers la fin de la grossesse, ou pendant le travail et l'accouchement. Plusieurs facteurs maternels et obstétricaux influencent les taux de transmission qui peuvent être réduits par l'administration de soins obstétricaux et médicaux optimaux. Il a été démontré qu'un traitement avec de la zidovudine réduit la transmission mère-enfant de façon significative, mais plusieurs questions, y compris celles de l'innocuité à court et à long terme des agents antirétroviraux et de l'utilisation optimale d'une thérapie antirétrovirale combinée pendant la grossesse, restent à être définies. Il est essentiel que les travailleurs de la santé qui assurent la prise en charge de ces femmes aient une parfaite compréhension de l'histoire naturelle de l'infection au VIH pendant la grossesse, des facteurs qui influencent la transmission verticale et des questions relatives à la prise en charge pendant la grossesse. Une étroite collaboration entre les membres d'une équipe multidisciplinaire de professionnels de la santé bien informés et, surtout, la femme elle-même, peuvent améliorer à la fois la santé de la mère et de l'enfant.

Winner of the 1998 The Canadian Journal of Infectious Diseases Trainee Review Article Award presented at the Canadian Infectious Disease Society Annual General Meeting, November 9, 1998

${ }^{1}$ Division of Infectious Diseases; ${ }^{2}$ Department of Medicine, Division of Infectious Diseases and Oak Tree Clinic, University of British Columbia, Vancouver, British Columbia

Correspondence: Dr David R Burdge, Oak Tree Clinic, B4W, 4500 Oak Street, Vancouver, British Columbia V6H 3N1. Telephone 604-875-2212,fax604-875-3063, e-mail dburdge@unixg.ubc.ca 
I n November 1997, the UNAIDS and World Health Organization (WHO) published revised global estimates for the numbers of people living with human immunodeficiency virus (HIV) infection and the numbers of people newly infected each year (1). Over 35 million people worldwide are believed to be living with HIV infection, and 16,000 new infections occur daily. Of the 5.2 million adults newly infected in 1997, 2.1 million were women (40\%), and the vast majority of those women are of childbearing age. Rates of infection in women of childbearing age continue to increase in both Canada and the United States, and from 1992 to 1996, women accounted for an all-time high of $20 \%$ of adults reported with AIDS in the United States (2). In British Columbia in 1995 and 1996, 24\% of the newly diagnosed HIV infections in the province were in women, almost all of whom were of childbearing age $(3,4)$. Furthermore, the UNAIDS and WHO estimate that 1.1 million children are living with HIV worldwide (1), 90\% of whom have acquired infection through vertical transmission (5). They also estimate that 8.2 million children have been orphaned by AIDS since the beginning of the epidemic (1). Therefore, it is clear that pregnancy and maternal-fetal transmission of HIV are already a huge global health care issue. It is critical that health care workers be educated about the natural history of HIV in pregnancy, the risk factors for vertical transmission and the potential opportunities for intervention.

Antiretroviral therapy (ART) with zidovudine has been demonstrated to decrease the risk of maternal-infant transmission significantly (6-8). However, current ART guidelines outside of pregnancy recommend triple combination regimens, designed to suppress the viral load, thereby minimizing the risk of viral resistance and prolonging quality survival (9). ART guidelines for pregnancy are also rapidly changing, and issues of concern include the immediate and long term health of the woman, fetal well-being, and minimizing the risk of maternal-infant transmission (10). Supportive nondirective counselling regarding reproductive choices, high risk prenatal care and modified management of labour and delivery are also important components of comprehensive care of pregnant women with HIV. This paper reviews the complex issues associated with HIV in pregnancy and provides some principles for appropriate care.

\section{NATURAL HISTORY}

HIV infection has not been associated with any definite embryopathy or teratogenic effect (11). A higher rate of spontaneous abortion and delivery of low birth weight infants may exist in women with advanced HIV disease (12). Two studies from New York, however, did not find a significant difference in spontaneous abortion rates between HIV-positive and -negative women $(13,14)$. Thus, aside from maternal-infant transmission, HIV has not been shown conclusively to alter pregnancy outcomes.

It was originally thought that the combination of pregnancy and HIV infection accelerated progression of HIV disease $(15,16)$. Pregnancy has traditionally been considered an immunosuppressive state. There appears to be a pregnancyrelated fall in $\mathrm{CD}_{4}$ counts in both HIV-infected and noninfected women, with incomplete recovery postpartum in HIV-infected women $(17,18)$. We believe, however, that the six-week postpartum $\mathrm{CD}_{4}$ cell count reflects the count that would have been expected due to disease progression with or without pregnancy.

To date, the effect of pregnancy on HIV-1 viral loads has only been evaluated in one study (19). Most of the women in this study had higher viral loads six months postpartum than prepartum. This postpartum increase was found regardless of whether women received zidovudine therapy during pregnancy and/or the postpartum period. None of these women received combination ART, and it is not known whether they had zidovudine-resistant virus postpartum. Further studies of the natural history of viral load through pregnancy are clearly needed. There is also a great need for better investigation of the potential adverse effects of even short term zidovudine monotherapy in pregnancy and the precise risk of zidovudine resistance.

Opportunistic infections that arise in pregnancy are related to the stage of HIV disease and degree of immunosuppression rather than the pregnancy itself. Pneumocystis carinii pneumonia may be more severe in pregnant women, presumably secondary to mechanical factors related to compression of the diaphragm. It remains a potential cause of maternal death (20). There have been reports that pregnancy-associated infections such as candidiasis and urinary tract infection occur at higher rates and with greater severity in the setting of HIV infection, but these reports have not been substantiated.

Two prospective studies have shown that pregnancy appears to have little impact on the natural history of HIV infection in women $(21,22)$. Berrebi et al (21) compared the evolution of clinical stages and laboratory parameters of HIV infection in pregnant and matched nonpregnant HIV-infected controls who were asymptomatic (stage II) or had generalized lymphadenopathy. They found no aggravating influence of pregnancy whether carried to term or interrupted (ie, aborted during first or second trimester) on the natural history of HIV in clinical stages II and III. Similarly, Alger et al (22) did not find any significant changes in $\mathrm{CD}_{4}$ or $\mathrm{CD}_{8}$ percentages or $\mathrm{CD}_{4}$ to $\mathrm{CD}_{8}$ ratio between prenatal and delivery measurements in HIV-infected women followed through pregnancy. They also found that the clinical status of these women changed little over the duration of prenatal care. Although seropositive women in the study were more likely to complain of at least one HIVrelated symptom (ie, oral thrush, recurrent fever, night sweats, weight loss), no single complaint increased during pregnancy.

\section{VERTICAL TRANSMISSION}

The major complication associated with HIV disease in pregnancy is the possible infection of the fetus or newborn. By the end of 1995 , more than $90 \%$ of children with AIDS acquired infection through vertical transmission (5). Perinatal transmission rates range from $14 \%$ to $39 \%$ (23-26), although transmission rates may be higher in women with more advanced disease (27). In the absence of ART, maternal-infant transmission rates in North America have consistently averaged $20 \%$ to $30 \%(6)$. 
Vertical transmission of HIV can occur in utero, intrapartum or postpartum through breastfeeding. It is thought that $50 \%$ to $70 \%$ of vertical transmission occurs just before or during the birth process $(28,29)$. Although in utero transmission does occur, it is likely of low frequency (30). There is evidence of HIV transmission to the fetus as early as the eighth week of gestation (31). However, peripartum transmission is likely the primary mode of vertical transmission of HIV. There are no congenital abnormalities associated with HIV, and less than one-half of infected children have detectable virus at birth, which supports this observation (32).

Postpartum transmission occurs primarily through breastfeeding. In the meta-analysis by Dunn et al (33), where data from prospective studies were used, women who breastfed had an increased risk of transmission, ranging from $7 \%$ to $22 \%$ above the rates of transmission in utero or in delivery. The European Collaborative Study (34) and the French Perinatal Study (35) also demonstrated a doubling in the risk of transmission with breastfeeding.

Maternal factors that have been shown to influence transmission include $\mathrm{CD}_{4}$ counts, viral characteristics and lifestyle issues. Low maternal $\mathrm{CD}_{4}$ counts, a low $\mathrm{CD}_{4}$ to $\mathrm{CD}_{8}$ ratio and the presence of p24 antigenemia were found to be associated with an increased risk of viral transmission in several studies $(25,36,37)$. These studies also showed that the risk of transmission increased during primary infection and in advanced disease. Interestingly, HIV-2 infection had a lower associated risk of vertical transmission than HIV-1 infection (38).

The influence of viral load on transmission rates has also been studied. A review of maternal plasma HIV-1 RNA levels in stored samples from women enrolled in the AIDS Clinical Trials Group (ACTG) 076 study found that vertical transmission occurred at all viral loads. In women receiving placebo, higher HIV-1 RNA levels did correlate with higher transmission rates, but this relationship was attenuated and not statistically significant in women receiving zidovudine (39). Zidovudine was effective in reducing transmission regardless of viral load. Several studies, involving small numbers of women, have shown an association between mother to child transmission and a high maternal plasma viral RNA load $(40,41)$. Other investigators, however, have shown that transmission is observed at all viral load levels and that the positive predictive value of viral load for transmission is low $(19,42,43)$. The effect of lowering viral load on vertical transmission rates requires further evaluation.

Maternal lifestyle factors that have been shown to influence vertical transmission include socioeconomic status and access to prenatal care, illicit drug use (44), multiple sexual partners (45) and nutritional status (vitamin A deficiency has been shown to increase transmission) (46).

No association has been found to date between sexually transmitted diseases and vertical transmission (37). Recently, however, a strong relationship has been shown between cervicovaginal shedding and several sexually transmitted diseases (gonorrhea, chylamidia infection, and cervical and vaginal ulcers) with a significant decrease in HIV shedding in women who were cured of their sexually transmitted disease (47).
This finding could explain why sexually transmitted diseases have been shown to be important risk factors for heterosexual transmission (48-50). Further research is needed to determine whether this increased shedding of HIV in cervicovaginal secretions in patients with sexually transmitted diseases does affect vertical transmission.

Other obstetrical issues have also been shown to be of importance in maternal-infant HIV transmission. Delivery before 37 weeks' gestation has been associated with increased HIV transmission rate (51). Preterm delivery occurs more frequently in advanced maternal disease and with maternal drug use, both of which may be independent risk factors contributing to increased transmission rates. With preterm delivery, the newborn has not had full transfer of maternal antibodies, which occurs late in pregnancy, and may therefore be at increased risk of acquiring infections including HIV during delivery. Low birth weight (less than $2500 \mathrm{~g}$ ) has also been reported as a risk factor for increased transmission and may be a marker of intrauterine infection. Moreover, low birth weight may be a sign of placental insufficiency, poor maternal nutrition or advanced maternal HIV disease.

Studies of twin deliveries add evidence to the hypothesis that most transmission occurs at delivery. Reports from the international registry of twins showed that the first-born twin was more likely to be infected with HIV than the second-born twin, leading to the conclusion that most HIV transmission occurs during passage through the birth canal (52). The study failed to control for obstetrical factors such as duration of rupture of membranes and monitoring with scalp electrodes. Increased infection risk in the first twin was present whether delivery was vaginal or by caesarian section. This suggests that factors other than direct contact with infected cervicovaginal secretions may also influence transmission. Ascending infection and prolonged rupture of membranes may be important factors in HIV transmission to the first born.

In a recent multivariate analysis, factors independently associated with increased risk of vertical transmission included low birth weight (less than $2500 \mathrm{~g}$ ), duration of ruptured membranes greater than $4 \mathrm{~h}$, low antenatal $\mathrm{CD}_{4}$ lymphocyte count (less than $29 \%$ of total lymphocytes) and illicit drug use during pregnancy (53). Among the women with more than $4 \mathrm{~h}$ of ruptured membranes before delivery, the rate of transmission was $25 \%$, compared with $14 \%$ among those who had less than $4 \mathrm{~h}$ of ruptured membranes. The presence of ruptured membranes doubled the risk of transmission, independent of the mode of delivery.

Several studies have evaluated the importance of the mode of delivery in vertical transmission. The European Collaborative Study (34) suggested that caesarian section approximately halves the risk of vertical transmission, even allowing for other factors known to increase transmission. The French Perinatal Study (35), however, showed no benefit of caesarian section in decreasing transmission. A meta-analysis of 11 studies, including the two large studies cited above, reported an odds ratio for caesarian section versus vaginal delivery of 0.8 (95\% CI 0.63 to $1.0, \mathrm{P}=0.05$ ) (54). This meta-analysis did not take into account other variables that affect vertical trans- 
mission. At the recent World AIDS Confernece (Geneva 1998) more Eurpoean data $(55,56)$ and a meatanalysis of 15 prospective cohort studies (57) was presented suggesting that csection may indeed be helpful in preventing perinatal transmission. More study is required to assess the exact factors associated with transmission at the time of delivery and the role of caesarian section in obstetrical management.

Other obstetrical factors of importance include the use of invasive monitoring, scalp electrodes and fetal scalp sampling, which were clearly shown to increase rates of vertical transmission (35). There have been suggestions that vaginal lavage with an antiseptic agent could decrease vaginocervical viral load and thus decrease transmission, but this has not been shown to decrease vertical transmission rates (58).

Therefore, it is clear that multiple factors influence maternal to infant HIV transmission. Transmission in utero is still not well understood, and further research is needed in this area. Maternal factors can be minimized by achieving low viral loads through ART, minimizing illicit drug use, maximizing nutrition, including vitamin A supplements, and ensuring optimal antenatal care for these women. Peripartum transmission can be decreased by limiting the use of invasive procedures, including scalp electrodes and artificial rupture of membranes, and by facilitating delivery within $4 \mathrm{~h}$ of the rupture of membranes. Current published recommendation are to reserve caesarian section for obstetrical indications other than HIV infection $(59,60)$. However, as data accumulats on the potential posotive impact on perinatal transmission, these published guidelines will no doubt be revised. For postpartum transmission, women should be educated regarding the risk of transmission by breastfeeding and should be discouraged from breastfeeding when other methods of nutrition are available.

\section{ART IN PREGNANCY}

There are important and unique issues associated with the use of ART in pregnancy. Treatment decisions must take into account the current and future health of the woman, the stage of pregnancy, the woman's wishes regarding the outcome of the pregnancy, the goal of preventing maternal-infant transmission, the well-being of the fetus and neonate, and unique pharmacokinetic considerations, including altered kinetics in pregnancy and issues of placental passage of medication. Until recently, zidovudine monotherapy was recommended for all pregnant HIV-infected women. However, current ART guidelines are much more complex, and are based on the principle that the woman should be offered optimal combination therapy in pregnancy, with full discussion of the potential risks and benefits (10).

The ATCG 076 was the first study showing reduction of perinatal transmission with the use of the antiretroviral agent zidovudine (6). This study was a randomized, multicentre, double-blind, placebo controlled trial. HIV-infected, zidovudine-naive pregnant women between 14 and 34 weeks' gestation, with $\mathrm{CD}_{4}$ counts of 200 cells $/ \mathrm{mm}^{3}$ or less, were randomly assigned to receive placebo or zidovudine. The treatment group received $100 \mathrm{mg}$ of zidovudine orally five times daily from enrolment until labour. During labour, intravenous zidovudine was administered in a $1 \mathrm{~h}$ loading dose of $2 \mathrm{mg} / \mathrm{kg}$ body weight, followed by a continuous infusion of $1 \mathrm{mg} / \mathrm{kg}$ body weight per hour until delivery. An oral dose of $2 \mathrm{mg} / \mathrm{kg}$ zidovudine syrup was given to the newborn every six hours for the first six weeks of life, beginning 8 to $12 \mathrm{~h}$ after birth. The placebo regimen was administered in an identical manner.

The ACTG 076 study showed a dramatic and statistically significant reduction in vertical transmission from a rate of $25.5 \%$ in the placebo group to a rate of $8.3 \%$ in the treatment group. Final results reported in 1996 were similar and continued follow-up of the infants has not shown toxicity up to five years of age, other than transient anemia seen in infants in the treatment arm. Congenital anomalies were seen equally in the treated and placebo groups.

There are still minimal data regarding the safety of zidovudine (or any other antiretroviral drug) in the first trimester of pregnancy because patients in the ACTG 076 study were all treated after 14 weeks. Other limitations of the ACTG 076 study include the lack of efficacy data in women who have advanced disease, who have received prior ART or who have zidovudine-resistant viral strains. The study was also not designed to identify the relative contributions of each component of the therapeutic regimen (ie, prepartum treatment versus peripartum treatment versus treatment of the infant after delivery). It is important to note, however, that the efficacy of the zidovudine protocol used in ACTG 076 has been proven subsequently in several clinical settings where a decline in transmission has been observed with zidovudine regardless of maternal $\mathrm{CD}_{4}$ count, duration of rupture of membranes, mode of delivery, gestational age and illicit drug use $(7,8,61)$.

While there are very limited safety data regarding any antiretroviral medication in pregnancy, an Antiretroviral Pregnancy Registry has been in operation since 1989. This is a cooperative effort among the Centers for Disease Control and Prevention (CDC), the National Institutes of Health, Glaxo Wellcome Inc, Hoffman-Laroche Inc, Bristol-Myers Squibb Co, and Merck \& Co. Its goal is to evaluate first trimester and other prenatal exposures to the following antiretrovirals: didanosine, indinavir, lamivudine, saquinavir, stavudine, zalcitabine and zidovudine. Findings are reported semiannually; they are intended to supplement animal toxicology studies and ongoing trial data, and aid clinicians in weighing the risks and benefits of treatment for individual patients. Registry findings to date show no increase in number of birth defects with zidovudine exposure in the first trimester compared with that expected in the general population. Insufficient data exist from the registry concerning the teratogenicity of other antiretrovirals alone or in combination. A similar registry is currently being developed through the MotherRisk program in Toronto, Ontario, and clinicians are encouraged to report the results of early ART in pregnancy to one or both of these pregnancy registries.

The United States Public Health Service has recently established new guidelines for the use of antiretroviral drugs in pregnancy (10). They emphasize the importance of using ART in pregnancy for maternal health indications in addition to re- 
ducing perinatal HIV transmission. The task force recommendations update the 1994 guidelines developed by the United States Public Health Service for use of zidovudine to reduce the risk of perinatal HIV transmission (62). These revised guidelines and the revised international panel (9) guidelines call for combination ART in pregnancy.

There are several potential advantages of combination therapy in pregnancy. More efficient reduction of maternal viral load may result in further decreases in transmission to the fetus (40). Decreasing viral load and increasing $\mathrm{CD}_{4}$ counts with multidrug therapy will also improve the overall immune status of the mother, thus decreasing the risk of opportunistic infections and the need for prophylactic medications in pregnancy. Combination therapy might decrease the risk of viral resistance compared with zidovudine monotherapy.

Given the very limited data regarding pharmacokinetics and the safety of antiretroviral drugs in pregnancy, all treatment decisions require full discussion with the woman regarding the known and unknown benefits and risks. British Columbia has recently developed new guidelines for ART in pregnancy, which are integrated into the BC Centre for Excellence in HIV/AIDS therapeutic guidelines (63). These guidelines are based on similar principles to those outlined in the draft United States Public Health Service document, and are listed in Table 1. Various clinical scenarios are presented in Table 2.

\section{PREVENTION OF OPPORTUNISTIC INFECTIONS IN PREGNANCY}

Prophylactic therapies to prevent opportunistic infections must be carefully addressed in any HIV-infected pregnant woman. The indications for prophylactic therapies are identical to those for nonpregnant adults.

Any pregnant woman with a $\mathrm{CD}_{4}$ count less than 200 cells $/ \mathrm{mm}^{3}$ should receive prophylaxis for Pneumocystis carinii. Trimethoprim/sulfamethoxazole, dapsone and aerosolized pentamidine can be safely administered in pregnancy. The treatment of choice remains trimethoprim/sulfamethoxazole because it has the greatest efficacy against $P$ carinii and provides prophylaxis against toxoplasma in very immunosuppressed women with positive toxoplasma serology. The concern with use of trimethoprim/sulfamethoxazole is the risk of kernicterus in the newborn (64). However, this potential risk does not alter this approach to Pneumocystis carinii prophylaxis in pregnancy. No adverse effects of dapsone use in pregnancy have been reported, but concern remains regarding its effect on the glucose-6-phosphate dehydrogenase system and, therefore, its use in pregnancy. Aerosolized pentamidine is safe, but is less efficacious than systemic prophylactic regimens and does not prevent extrapulmonary disease.

For HIV-infected women with a $\mathrm{CD}_{4}$ count less than 75 cells $/ \mathrm{mm}^{3}$, Mycobacterium avium complex (MAC) prophylaxis should be offered. There are limited data available but rifabutin does not appear to carry any specific risk for the fetus in the pregnant woman. A macrolide such as clarithromycin or azithromycin should be considered and is likely preferable in terms of both efficacy and safety.

HIV-infected women requiring acyclovir for herpes prophy-
TABLE 1

Therapeutic strategies for the treatment of pregnant women infected with human immunodeficiency virus (HIV)

1. All HIV-infected pregnant women should be offered optimal combination antiretroviral therapy with full discussion and consideration of the known and unknown benefits and risks of such therapy in pregnancy.

2. A woman's informed treatment choices must be respected.

3. Zidovudine should be included whenever appropriate in the antiretroviral regimen (if appropriate to the care of the mother) because it remains the only drug shown to reduce perinatal transmission.

4. Whenever possible antiretrovirals known to have good placental passage (zidovudine, 3TC, d4T, nevirapine) should be used.

5. Avoid, whenever possible, drugs with unknown teratogenicity during the period of organogenesis (first trimester).

6. Careful consideration should be given to delaying initiation of new combination ART until after 14 to 18 weeks' gestation (and whenever possible after detailed ultrasound at 18 weeks) unless early initiation of therapy is judged to be important for maternal health.

7. If a pregnant woman has significant nausea of pregnancy, do not begin antiretroviral therapy until nausea is adequately controlled. Diclectin (Duchesnay) (two tablets at bedtime, and one tablet morning and midafternoon if needed) can be used with antiretrovirals. If the woman is already on antiretrovirals and has hyperemesis of pregnancy, discontinue all drugs at once and reinstate all at once when nausea and vomiting are controlled.

8. If antiretroviral therapy is discontinued for any reason during pregnancy, discontinue all drugs at once, and resume all drugs simultaneously to minimize the risk of viral resistance developing in therapy.

9. Therapy should be individualized to maximize adherence to the prescribed antiretroviral regimen.

10. The women's clinical, virological and immunological status should be assessed at least once each trimester, and again six weeks post partum. Routine criteria of response to, and failure of ART should be employed.

11. Breastfeeding is not recommended regardless of ART.

12. Further research is needed, and whenever possible women should be offered involvement in clinical trials in pregnancy.

13. Consult with HIV specialists in this complex field.

laxis can take it safely in the second and third trimesters after the time of organogenesis. However, if the benefits are felt to outweigh the risks, this medication could also be given in the first trimester.

\section{MANAGEMENT OF HIV IN PREGNANCY}

HIV testing: All pregnant women should be offered testing for HIV at the time of their first perinatal visit. Testing of women with history of high risk behaviour alone may miss up to half of pregnant women with HIV (65). Counselling and HIV testing for all pregnant women is recommended by the Society of Obstetricians and Gynaecologists of Canada (59), the International Panel (66) and the CDC (67). We recommed repeat HIV testing each trimester and toward term in women who were seronegative on initial testing, but have continued with high risk behaviours in pregnancy. The majority of women agree to 
TABLE 2

\section{Clinical scenarios}

\section{Clinical scenario}

HIV-infected pregnant women on no antiretroviral therapy (ART) when pregnancy is diagnosed

HIV-infected pregnant women receiving combination ART when pregnancy is diagnosed

HIV-infected woman in labour who has had no prior ART

Infants born to mothers who have received no ART in pregnancy or intrapartum

Primary HIV infection (seroconversion) in pregnancy*

\section{Recommended response}

Assess the woman's clinical, virological and immunological status. Regardless of viral load and $\mathrm{CD}_{4}$ cell count, all pregnant women should be offered combination therapy, with full discussion and consideration of known and unknown benefits or risks of such therapy in pregnancy.

In most circumstances, initiation of ART should be delayed until after the first trimester (and consideration should be given to waiting for a detailed ultrasound assessment at 18 weeks), unless early initiation is judged to be important for maternal health.

ART should be chosen carefully on the basis of the principles outlined above, and the available information regarding potential toxicities of individual agents in pregnancy.

Reassess clinical immunological and virological status at lease once each trimester, and again six weeks postpartum.

Regardless of the ART given to the woman, all women should receive intravenous zidovudine at labour and delivery, and the infant should receive oral zidovudine in an attempt to reduce perinatal transmission.

Women who decline combination ART after appropriate counselling and education should be offered the three-part zidovudine chemoprophylaxis regimen (oral after 14 to 18 weeks' gestation, intravenous at labour and delivery, and oral to the infant) in an attempt to reduce perinatal transmission. Women who choose this therapy to minimize exposure of their fetus to other drugs should be informed of the potential risk of resistance developing on zidovudine monotherapy. Oral zidovudine should be discontinued in the mother at labour and delivery, and she should be reassessed postpartum for combination ART.

Combination ART regimens should be interrupted for as short a period as possible during labour and delivery. Discussion of treatment options and recommendations must be noncoercive, and the final decision regarding the use of these drugs is the responsibility of the woman.

Continue existing combination therapy regimen, provided the regimen is judged to be effective according to usual criteria.

If the existing effective regimen does not contain zidovudine, and the patient is not intolerant or known to be resistant to zidovudine, consider switching one of nucleoside analogues to zidovudine. Continue zidovudinecontaining combination until term, and offer intravenous zidovudine in labour and oral zidovudine to neonate. If the patient has been clearly intolerant to zidovudine in the past (but not likely resistant), continue the currently effective regimen, and give intravenous zidovudine at term, and oral zidovudine therapy to neonate.

If the current regimen is not controlling viral replication, switch to a new regimen on the basis of previous history of antiretroviral use and the likelihood of cross-resistance. Choose drugs on basis of the principles outlined above.

Monitor $\mathrm{CD}_{4}$ and viral load every two to three months through the pregnancy and again six months postpartum.

If a woman chooses to discontinue the ART therapy during the first trimester, discontinue all drugs at once, and resume all drugs together at 14 to 18 weeks' gestation (or whenever possible after detailed ultrasound at 18 weeks) in order to minimize risk of developing viral resistance.

Offer intrapartum intravenous zidovudine during delivery and six weeks of postpartum zidovudine to neonate as per prophylaxis protocol.

Complete assessment postpartum (viral load, $\mathrm{CD}_{4}$, etc), and offer combination ART as per nonpregnant adult guidelines.

Oral zidovudine should be discussed with the mother and offered to the newborn, starting as soon as possible after birth, preferably within 12 to $24 \mathrm{~h}$ of birth.

The woman should be assessed postpartum (viral load, $\mathrm{CD}_{4}$, etc) and offered combination ART as per nonpregnant adult guidelines.

Women should be carefully counselled in a noncoercive manner regarding reproductive choices, and supported in their choices.

If a woman chooses to initiate combination ART, it should be started as soon as possible, regardless of gestational age.

If a woman with primary infection chooses to continue the pregnancy and refuses combination therapy, offer zidovudine chemoprophylaxis protocol to reduce perinatal infection.

*Documented primary infection may represent an indication for triple combination ART. This is important for long term maternal well being, and is also likely of benefit to the fetus, given that primary infection represents a scenario where the risk of maternal-infant transmission is likely higher than in women who seroconvert before pregnancy 
testing in pregnancy if it is offered to them. We recommend repeat HIV testing each trimester and toward term in women who were seronegative at initial testing, but have continued with high risk behaviours in pregnancy.

For some women, pregnancy may be their first and only interaction with any health care provider or health care system and is an ideal time to offer testing. Diagnosis of HIV in women results in the ability to offer therapies that will improve the long term health and prognosis of the woman, reduce the risk of vertical transmission of HIV and potentially lead to the formation of a relationship with the health care system to encourage long term follow-up and treatment. If women are judged to be at high risk or continue to practise high risk behaviour for HIV acquisition, they should be offered retesting in the third trimester of pregnancy.

Prepregnancy management: Women who are known to be HIV-positive and wish to become pregnant should be counselled by an experienced and knowledgeable person in a nondirected manner. The lack of impact of pregnancy on HIV disease, the risk of HIV disease on pregnancy, the risks of perinatal transmission and nature of HIV disease in children should be outlined in a nonjudgemental fashion. The general health and nutritional status of the mother should be optimized and routine prenatal recommendations, such as prepregnancy folic acid supplementation, should be reviewed. Every effort should be made to optimize ART, minimize viral load, maximize $\mathrm{CD}_{4}$ counts, prophylax and treat any opportunistic infections, and optimize ART before the woman becomes pregnant.

Prenatal management: When a woman who is known to be HIV-positive becomes pregnant or a woman is identified to be HIV-positive on prenatal screening, the ideal prenatal management situation is having a multidisciplinary team involved in her care. If possible, this team should include obstetricians and other physicians experienced in HIV, pharmacists, nutritionists, psychologists, and social workers. The woman herself is a vital part of the team and must be involved in all decisions. An experienced member of the team should provide noncoercive counselling. Issues to be addressed include the impact on the patient of any recent HIV diagnosis identified by screening; the risk of vertical transmission and methods available to decrease this risk, including discussion of ART in pregnancy (outlined above); support and counselling in making informed reproductive decisions; general counselling on decreasing the transmission of HIV to others; and referral for psychological, social and other support services as necessary.

The patient should undergo a complete history and physical examination including an obstetrical and gynecological history with cytological smear and endocervical swab for gonococcus, chlamydia and group B streptococcus. The cytological smear should be repeated eight weeks after the initial test, and repeat endocervical swabs for chlamydia and gonococcus should be done in the third trimester. At each visit, fetal growth should be assessed, and early signs and symptoms of opportunistic infections should be sought. Special attention should be paid to the oropharyngeal cavity, and cervicovaginal inflammation and infection should be ruled out at each visit and treated as necessary.
Blood work should include routine prenatal blood tests. $\mathrm{CD}_{4}$ levels and viral load should be determined at the first visit and should be repeated each trimester. Routine HIV screening, including tuberculin skin test and serologies for toxoplasma, cytomegalovirus, herpes simplex virus, syphilis, and hepatitis $B$ and $C$, should be done if not already available. A urine sample should be taken and sent for routine microbiology. Ultrasound should be performed for routine obstetrical indications. The authors' personal preference is to perform detailed obstetrical ultrasound at 18 weeks, before institution of combination ART (in women not already receiving such therapy).

Vaccinations should be updated, and the potential need for prophylactic therapies should be addressed. Live and attenuated vaccines should be avoided in pregnancy. The following vaccines should be offered: pneumococcal, hepatitis B (if serology is negative), influenza and diphtheria/tetanus. The indications for $P$ carinii and MAC prophylaxis are the same as in the nonpregnant adult.

If possible, a nutritionist should also be consulted. Routine vitamin supplementation, including iron and folic acid, should be advised. Psychosocial supports and the need for social services referral should be assessed at each visit. Finally, the use of ART and prophylactic therapy for opportunistic infections should be reviewed at each visit, following the principles already outlined.

Intrapartum management: Universal infection control precautions should be maintained throughout the intrapartum period. Exposure of the fetus to maternal secretions should be minimized. Fetal scalp electrodes and sampling as well as augmented rupture of membranes should be avoided unless absolutely necessary. Early identification and treatment of chorioamnionitis are advised.

Although current published recommendations are to preserve caesarian section for other obstetrical indications, further data have recently been published suggesting that caesarian section may in fact contribute to decreased HIV perinatal transmission rates. The precise role of caesarian section in the obstetrical managment of HIV-positive women remains to be defined. We are currently offering caesarian section to women with prolonged rupture of membranes, any obstetrical complication that would potentially prolong any stage of labour, women who were either diagnosed late in pregnancy or for any reason have not been established on antiretroviral therapy in pregnancy, and to women where the viral load is not well controlled despite antiretroviral therapy in pregnancy. If a caesarian section is performed, the patient should receive routine antibiotic prophylaxis. There are no contraindications to the use of anesthesia during delivery, including epidural anesthetics.

Because most vertical transmission of HIV likely occurs during the intrapartum period, the intrapartum component of ART may be important. All HIV-infected women should be offered zidovudine therapy intravenously during the intrapartum period, regardless of whether they have been on ART through the pregnancy. A loading dose of zidovudine should be administered at the onset of labour, following rupture of membranes, $1 \mathrm{~h}$ before elective caesarian section or in any 
situation in which delivery is anticipated. If the patient does not deliver, oral ART should be restarted.

Postpartum management: After delivery, the infant should be washed with an antiseptic soap and water to remove all maternal and amniotic secretions before any injections or blood sampling. Cord blood should be sent for routine blood work as well as serology for syphilis, hepatitis B and toxoplasmosis. Hepatitis B immune globulin and vaccine should be administered to the infant if the mother is hepatitis surface antigen-positive. After $24 \mathrm{~h}$, an HIV culture, polymerase chain reaction and p24 antigen should be sent to a reference laboratory. The infant should be considered for zidovudine therapy whether or not the mother has received ART in pregnancy (10). Women who are not receiving ART in pregnancy should be assessed for, and offered, optimal combination therapy in the postpartum period.

Breastfeeding should be avoided if other sources of nutrition are available. Contraceptive methods should be discussed, HIV transmission prevention methods should be reviewed, and the need for social services and other support should be assessed.

\section{CONCLUSIONS}

Growing numbers of women in their childbearing years are becoming infected with HIV. Optimal care of these women when they become pregnant is complex and best accomplished through a multidisciplinary team of HIV-knowledgeable health care professionals. It is imperative that the woman herself is an integral member of the team, and her reproductive choices and informed treatment decisions must be respected. It is important to note that in developing countries, where health care resources are limited, the management strategies outlined in this paper may be difficult or impossible to achieve at present.

Careful systematic research is still needed for many aspects of HIV in pregnancy. The potential role of vitamin A supplements, the precise role of caesarean section and the optimal approach to ART in pregnancy need further elucidation. Only through collaborative investigations will the care and outcome of HIV-infected pregnant women and their infants be significantly enhanced.

\section{REFERENCES}

1. UNAIDS and World Health Organization. Report on the Global HIV/AIDS Epidemic Dec 1997. Geneva: UNAIDS Publication, 26 Nov 1997:1-25.

2. United States Department of Health and Human Services, Centers for Disease Control and Prevention. Trends in AIDS incidence, death and prevalence - United States, 1996. Morb Mortal Wkly Rep 1997;46:165-73.

3. Wong E, MacDougall RG, Patrick DM, et al. AIDS Update Quarterly Report, $4^{\text {th }}$ quarter. Victoria: British Columbia Centre for Disease Control, 1995:1-30.

4. Wong E, MacDougall RG, Patrick DM, et alAIDS Update Quarterly Report, $4^{\text {th }}$ quarter. Victoria: British Columbia Centre for Disease Control, 1996:1-45.

5. Centers for Disease Control and Prevention. HIV/AIDS Surveillance Report. Atlanta: Public Health Service - 1995.

6. Connor EM, Sperling R, Gelber R, et al. Reduction of maternal-infant transmission of human immunodeficiency virus type 1 with zidovudine treatment. $\mathrm{N}$ Engl J Med 1994;331:1173-80.

7. Blanche S, Mayaux MJ, Mandelbrot L, Rouzioux C, Delfraissy F. Acceptability and impact of zidovudine prevention on mother to child HIV-1 transmission in France. 4th Conference on Retroviruses and Opportunistic Infections, Washington DC, January 22-26,1997. (Abst 380)

8. Fiscus SA, Adimora AA, Schoenbach VJ, et al. Perinatal HIV infection and transmission and the effect of zidovudine therapy on transmission in rural and urban counties. JAMA 1996;275:1483-8.

9. Carpenter CC, Fischl MA, Hammer SM, et al. Antiretroviral therapy for HIV infection in 1997: Updated recommendations of International AIDS Society - USA Panel. JAMA 1997;277:1962-8.

10. Public Health Service Task Force. Recommendations for the use of antiretroviral drugs in pregnant women infected with HIV-1 for maternal health and for reducing perinatal HIV-1 transmission in US. Morb Mortal Wkly Rep 1998;47:1-30.

11. Broosard Y, Aubin J-T, Mandelbrot L, et al. Frequency of early in utero HIV-1 infection: A blind DNA polymerase chain reaction study on 100 fetal thymuses. AIDS 1995;9:359-66.

12. Johnstone FD, MacCallum L, Brettle R, et al. Does infection with HIV affect the outcome of pregnancy? Br Med J (Clin Res Ed) 1988;296:467.

13. Selwyn PA, Schoenbaum EE, Davenny K, et al. Prospective study of human immunodeficiency virus and pregnancy outcomes in intravenous drug users. JAMA 1989;262:1289-94.

14. Sunderland A, Minkoff HL, Handte J, et al. The impact of human immunodeficiency virus serostatus on reproductive decisions of women. Obstet Gynecol 1992;79:1027-31.

15. Scott GB, Fischl MA, Klimas N, et al. Mothers of infants with acquired immonudeficiency syndrome: Evidence for both symptomatic and asymptomatic carriers. JAMA 1985;253:363-6.

16. Minkoff H, Nanda D, Menez R, Fikrig S. Pregnancies resulting in infants with acquired immunodeficiency syndrome or AIDS-related complex. Obstet Gynecol 1987;320:1637-42.

17. Rich KC, Siegal JN, Jennings C, Rydman RJ, Londay AL. $\mathrm{CD}_{4}+$ lymphocytes in perinatal human immunodeficiency virus (HIV) infection: Evidence for pregnancy-induced immune depression in uninfected and HIV-infected women. J Infect Dis 1995;172:1221-7.

18. Biggar RJ, Pahwa S, Minkoff H, et al. Immunosuppression in pregnant women infected with human immunodeficiency virus. Am J Obstet Gynecol 1989;161:1239-44.

19. Cao Y, Krogstad P, Korber BT, et al. Maternal HIV-1 viral load and vertical transmission of infection: The Ariel Project for the prevention of HIV transmission from mother to infant. Nat Med 1997;3:549-52.

20. Minkoff H, de Regt RH, Landesman S, Schwartz R. Pneumocystis carinii pneumonia associated with acquired immunodeficiency syndrome in pregnancy: a report of three maternal deaths. Obstet Gynecol 1986;67:284-7.

21. Berrebi A, Kobuch WE, Puel J. Influence of pregnancy on human immunodeficiency virus disease. Eur J Obstet Gynecol Reprod Biol 1990;37:211-7.

22. Alger LS, Farley JJ, Robinson BA, et al. Interactions of human immunodeficiency virus infection and pregnancy. Obstet Gynecol 1993;82:787-96.

23. Blanche S, Rouzioux C, Moscato MG, et al. A prospective study of infants born to women seropositive for human immunodeficiency virus type 1. N Engl J Med 1989;320:1643-8.

24. Hira SK, Kamanga J, Bhat GJ, et al. Perinatal transmission of HIV-1 in Zambia. Br Med J 1989;299:1250-2.

25. Newell ML, Dunn D, Peckham CS, et al. European Collaborative Study: Risk factors for mother to child transmission of HIV-1. Lancet 1992;339:1007-12.

26. Ryder RW, Nsa W, Hassig SE, et al. Perinatal transmission of the human immunodeficiency virus type 1 to infants of seropositive women in Zaire. $\mathrm{N}$ Engl J Med 1989;320:1637-42.

27. Goedert JJ, Mendez H, Drummond JE, et al. Mother to infant transmission of human immunodeficiency virus type 1: Association with prematurity or low anti-gp 120. Lancet 1989;ii:1351-4.

28. Boyer PJ, Dillon M, Navaie M, et al. Factors predictive of maternal-fetal transmission of HIV-1: preliminary analysis of zidovudine given during pregnancy and/or delivery. JAMA 1994;271:1925-30.

29. Rouzioux C, Costagliola D, Burgard M, et al. Timing of mother to 
child HIV-1 transmission depends on maternal status. AIDS 1993;7(Suppl 2):549-52.

30. Brossard Y, Bignozzi C, Mandelbrot L, et al. PCR prevalence of HIV in 99 fetal thymuses at mid-gestation. Abstracts of the IXth International Conference on AIDS, Berlin, 1993. (Abst PO-B05-1038)

31. Lewis SH, Reynolds-Kohler C, Fox HE, Nelson JA. HIV-1 trophoblastic and villous Hofbauer cells and hematological precursors in eight-week fetuses. Lancet 1990;335:565-8.

32. Ehrnst A, Lindgren S, Dictor M, et al. HIV in pregnant women and their offspring: evidence for late transmission. Lancet 1991;336:203-7.

33. Dunn DT, Newell ML, Ades A, Peckham C. Risk of human immunodeficiency virus type 1 transmission through breastfeeding. Lancet 1992;340:585-8.

34. Newell ML, Dunn DT, Peckham CS, et al. Caesarian section and risk of vertical transmission of HIV-1 infection. European Collaborative Study. Lancet 1994;343:1464-7.

35. Mandelbrot L, Mayaux MJ, Bongain A, et al. Obstetric factors and mother-to-child transmission of human immunodeficiency virus type 1: the French perinatal cohort. Am J Obstet Gynecol 1996;175:661-7.

36. Mayaux MJ, Blanche s, Rouzioux C, et al. Maternal factors associated with perinatal transmission: The French cohort study -7 years of follow-up observation. J Acquir Immune Def Syndr Hum Retrovirol 1995;8:188-94.

37. St Louis ME, Kamenga M, Brown C, et al. Risk for perinatal HIV-1 transmission according to maternal immunologic, virologic and placental factors. JAMA 1993;269:2853-9.

38. Adjorlolo-Johson G, De Cock K, Ekpini E, et al. Prospective comparison of mother to child transmission of HIV-1 and HIV-2 in Abidjan, Ivory Coast. JAMA 1994;272:462-6.

39. Sperling RS, Shapiro DE, Coombs R, et al. Maternal viral load, zidovudine treatment, and the risk of transmission of human immunodeficiency virus from mother to infant. N Engl J Med 1996;335:1621-9.

40. Coll O, Hernandez M, Boucherm CAB, et al. Vertical transmission correlates with a high maternal viral load at delivery. J Acquir Immune Def Syndr Hum Retrovirol 1997;14:26-30.

41. Dickover RE, Gatratty EM, Herma SA, et al. Identification of levels of maternal HIV-1 RNA associated with risk of perinatal transmission. JAMA 1996;275:599-605.

42. Mayaux M-J, Dussaix E, Isopet J, et al. Maternal virus load during pregnancy and the mother-to-child transmission of human immunodeficiency virus type I: the French Perinatal Cohort Studies. J Infect Dis 1997;175:172-5.

43. Thea DM, Steketee RW, Bornshlegel K, et al. The effect of maternal viral load on the risk of perinatal transmission of HIV-1. J Infect Dis 1997;175:707-11.

44. Rodriguez EM, Mofenson LM, Bei-Hung C, et al. Association of maternal drug use during pregnancy with maternal HIV culture positivity and perinatal HIV transmission. AIDS 1996;10:273-82.

45. Bulterys M, Chao A, Dushimimana A, et al. Multiple sexual partners and mother-to-child transmission of HIV-1. AIDS 1995; 7:1639-45.

46. Semba RD, Miooti PG, Chiphangwi JD, et al. Maternal vitamin A deficiency and mother-to-child transmission of HIV-1. Lancet 1994;343:1593-7.

47. Ghys PD, Fransen K, Diallo MO, et al. The associations between cervicovaginal HIV shedding, sexually transmitted diseases and immunosuppression in female sex workers in Abidjan, Côte d'Ivoire. AIDS 1997;11:F85-93.

48. Cameron DW, Simonsen JN, D'Costa CJ, et al. Female to male transmission of human immunodeficiency virus type 1: risk factors for seroconversion in men. Lancet 1989;ii:403-7.

49. Plummer FA, Simonsen JN, Cameron DW, et al. Cofactors in male-female sexual transmission of of human immunodeficiency virus type 1. J Infect Dis 1991;163:233-9.
50. Grosskurth H, Mosha F, Todd J, et al. Impact of improved treatment of sexually transmitted diseases on HIV infection in rural Tanzania: randomized controlled trial. Lancet 1995;346:530-6.

51. Minkoff $\mathrm{H}$, Mofenson LM. The role of obstetric interventions in the prevention of pediatric human immunodeficiency virus infection. Am J Obstet Gynecol 1994;171:1167-74.

52. Goedert JT, Duliege AM, Amos CI. High risk of HIV-1 infection for first born twins. Lancet 1991;338:1471-5.

53. Landesman SH, Kalish LA, Burns DN, et al. Obstetrical factors and the transmission of human immunodeficiency virus type 1 from mother to child. N Engl J Med 1996;334:1617-65.

54. Dunn DT, Newell ML, Mayaux C, et al. Mode of delivery and vertical transmission of HIV-1: A review of prospective studies. J Acquir Immune Def Syndr Hum Retrovirol 1994;7:1064-6.

55. Lutz-Friedrich R, Buchholz B, Klarmann D, et al. Combining ZVD treatment and elective cesarean section reduces the vertical transmission of HIV 1 below 3\% in the German perinatal cohorts. 12th World AIDS Conference, Geneva, June 28-July 3, 1998. (Abst 23291)

56. Mandelbrot L, Le Chenadec J, Berrebi A, et al. Decreased perinatal HIV-1 transmission following elective cesarean delivery with zidovudine treatment. 12th World AIDS Conference, Geneva, June 28-July 3, 1998. (Abst 23272)

57. Read J. Mode of delivery and vertical transmission of HIV-1: A meta-analysis from fifteen prospective cohort studies (The International Perinatal HIV Group). 12th World AIDS Conference, Geneva, June 28-July 3, 1998. (Abst 23275)

58. Biggar RJ, Miotti PG, Taha TE, et al. Perinatal intervention trial in Africa: Effect of a birth canal cleansing to prevent HIV transmission. Lancet 1996;347:1647-50.

59. The National Working Group on "Practice Guidleines for Obstetrical and Gynecological Care of Women Living with AIDS". In: Steben M, Mensah MN, Bally GA, Taylor PJ, eds. Practice Guidelines for Obstetrical and Gynecological Care of Women Living with HIV. Ottawa: The Society of Obstetricians and Gynaecologists of Canada, 1994:1-19.

60. Zorilla $\mathrm{CD}$. Obstetric factors and mother to infant transmission of HIV-1. Infect Dis Clin North Am 1997;2:109-18.

61. Cooper ER, Nugent RP, Diaz C, et al. After AIDS Clinical Trial 076: the changing pattern of zidovudine use during pregnancy, and the transmission of human immunodeficiency virus in a cohort of infected women and their infants. J Infect Dis 1996; 174:1207-11.

62. Centers for Disease Control and Prevention. Recommendations for the use of zidovudine to reduce perinatal transmission of human immunodeficiency virus. Morb Mortal Wkly Rep 1994;43:1-20.

63. British Columbia Centre for Excellence in HIV/AIDS. Therapeutic Guidelines for the Treatment of HIV/AIDS and Related Conditions: Section 5: Women and HIV. Vancouver: British Columbia Centre for Excellence in HIV/AIDS, 1998:S51-S52b

64. Silverman WA, Anderson DH, Blanc WA, Crozier DN. A difference in mortality rate and incidence of kernicterus among premature infants allotted to two prophylactic antibacterial regimens. Pediatrics 1956;18:614-25.

65. Barbacci MB, Dalabetta GA, Repke JT, et al. Human immunodeficiency virus infection in women attending an inner-city prenatal clinic: ineffectiveness of targeted screening. Sex Transm Dis 1990;17:122-6.

66. Carpenter CC, Fischl MA, Hammer SM, et al. Antiretroviral therapy for HIV infection in 1996. Recommendations of an international panel. International AIDS Society - USA. JAMA 1996;276:146-54.

67. Centers for Disease Control and Prevention. US Public Health Service recommendations for human immunodeficiency virus counseling and voluntary testing for pregnant women. Morb Mortal Wkly Rep 1995;44:1-15. 


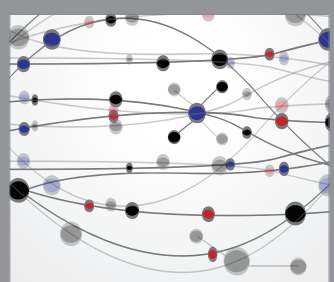

The Scientific World Journal
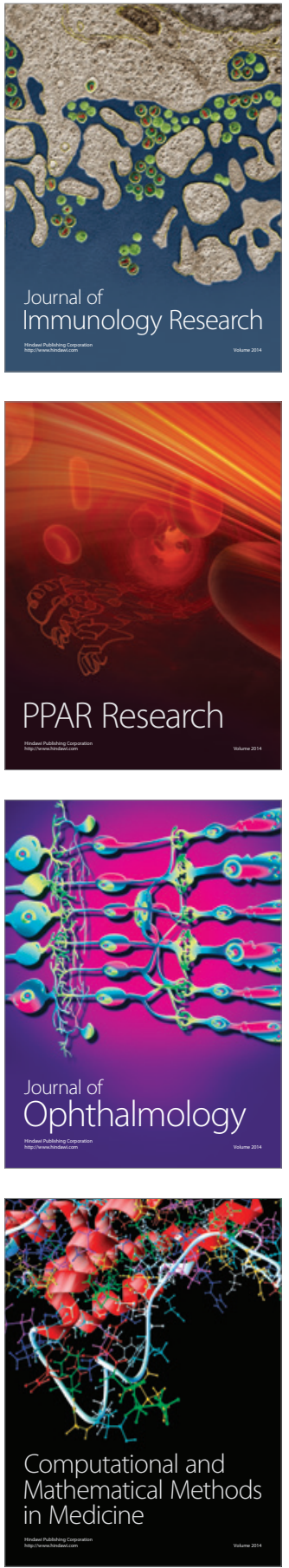

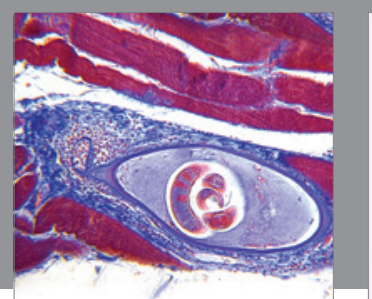

Gastroenterology Research and Practice

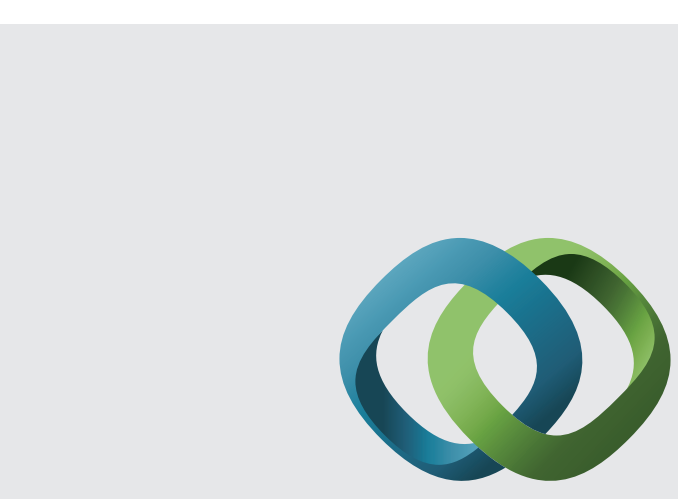

\section{Hindawi}

Submit your manuscripts at

http://www.hindawi.com
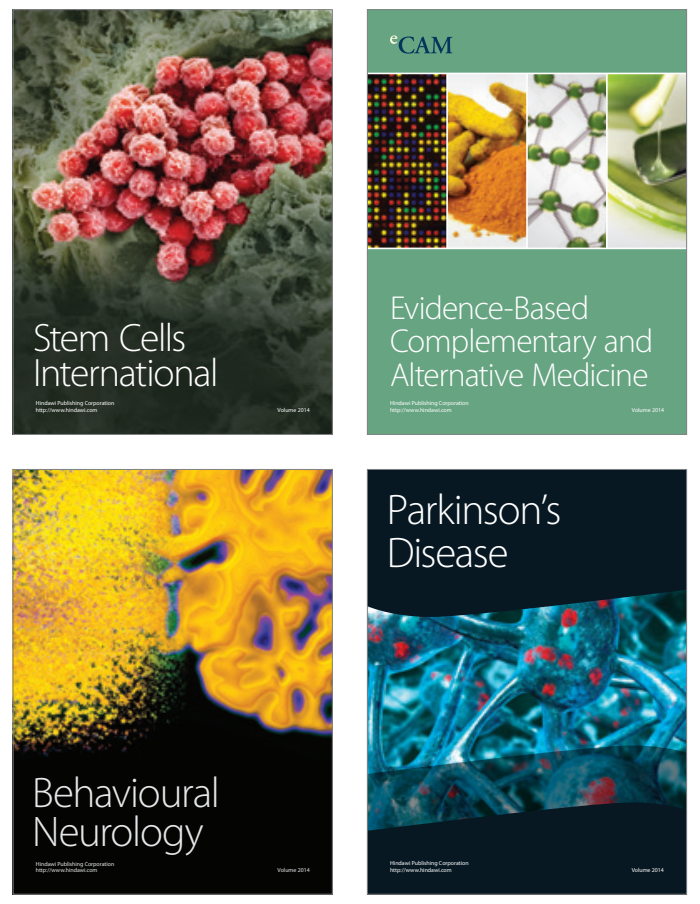
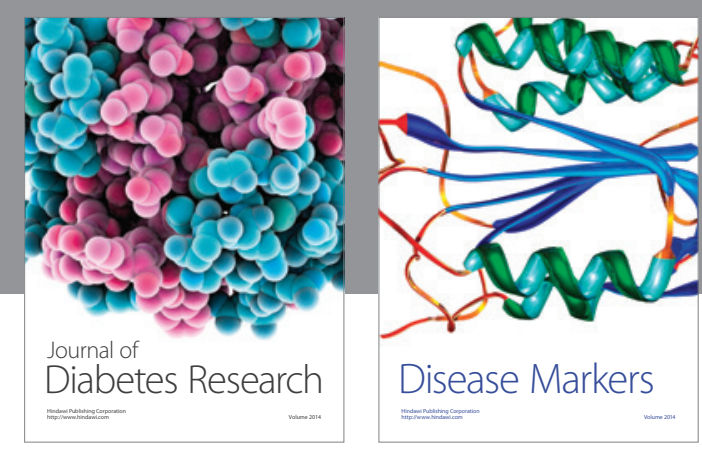

Disease Markers
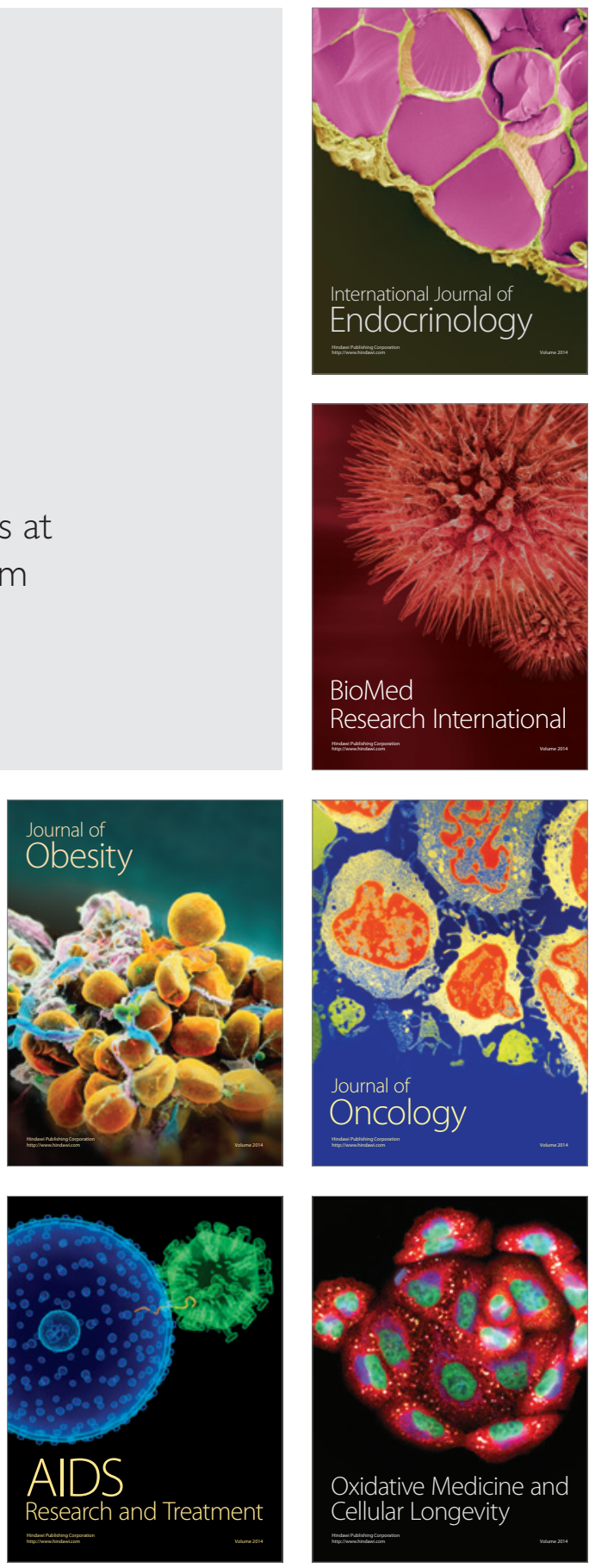